\title{
In vitro antimicrobial activity and the major polyphenol in leaf extract of Mangifera
} indica $\mathrm{L}$.

\author{
Masibo, M. ${ }^{1^{*}}$ and $\mathrm{He}, \mathrm{Q}^{2}$ \\ ${ }^{1}$ Food and Agricultural Products Laboratory, Kenya Bureau of Standards (KEBS)-54974, \\ Nairobi, Kenya. \\ ${ }^{2}$ Jiangnan University, School of Food Science and Technology, Food Safety and Quality Control Laboratory, Wuxi - \\ 214122, Jiangsu Province, China. \\ E-mail:masibomsc@gmail.com
}

Received 3 February 2009; received in revised form 24 April 2009; accepted 24 April 2009

\begin{abstract}
Use of plant extracts as antimicrobials has recently gained wide attention over the continued use of synthetic antibiotics. In this work, Chinese mango leaves were subjected to different extraction regimes namely decoction $\left(50{ }^{\circ} \mathrm{C}\right.$ for $48 \mathrm{~h}$ and boiling for $3 \mathrm{~h}$ ) and solvent extraction (50\% ethanolic solution at $62{ }^{\circ} \mathrm{C}$ for $1 \mathrm{~h}$ ). The extract solutions were lyophilized yielding 24-26\% powdered extracts that were used for the antimicrobial tests against four pathogenic (Salmonella typhi, Escherichia coli, Staphylococcus aureus, Bacillus cereus) and two generally regarded as safe (Streptococcus thermophilus, and Lactobacillus acidophilus) microbial strains. Antimicrobial activity was assessed by inhibition diameters which were found to range from 9-15.5 $\mathrm{mm}$ for the three extracts against all the bacterial strains tested and inhibition growth curves which showed the extracts as first acting within the first 20 min after which a steady state (bacteriostatic) was attained and maintained throughout the testing time (360 min) with a significant difference $(p<0.05)$ from the negative control. The minimum inhibitory concentrations for the extracts were later determined by two fold serial dilutions method and they ranged from $36.2-18.2 \mathrm{mg} / \mathrm{mL}$ against all the strains. The extracts were then subjected to reversed-phase HPLC to identify and quantify the polyphenol mangiferin which was found to be the abundant compound in the extracts at $100 \mu \mathrm{g} / \mathrm{mL}$ with no significant difference $(p<0.05)$ in quantity among the three extracts.
\end{abstract}

Keywords: mango, polyphenol, mangiferin, HPLC, MIC, antibiotic, lyophilization, inhibition zone

\section{INTRODUCTION}

In recent times, there has been increasing interest in the study of bioactive compounds from mango pulp, peels, seeds, leaves, flowers, and stem bark due to their antioxidative, antimicrobial and other health promoting properties that make consumption of mangoes and its derived products a healthy habit (Nunez-Selles, 2005; Masibo and He, 2008). The Mango (Mangifera indica L.) is the most economically important plant in the family Anacardiaceae, with India being the world's largest producer. The primary mango product is the mature whole fruit, the pulp of which can be consumed, raw or processed into a variety of products whereas utilization and consumption of the mango peel and seed has also been reported (Puravankara et al., 2000). The aqueous leaf extract of $M$. indica has been reported to be rich in polyphenols amongst which mangiferin has been extensively studied by several authors and proposed as the bioactive principle of $M$. indica $L$. stem bark and leaf extracts possess several pharmacological activities including antioxidant, analgesic, antidiabetic, antiinflammatory, antitumor, immunomodulatory and anti-HIV effects (Nunez-Selles, 2005). Besides mangiferin, there is a wide array of other polyphenols and microelements both known and unknown in the leaves and stem bark extracts of the mango, all of which play a role in their pharmaceutical potential.

Since the advent of antibiotics in the 1950s, the use of plant derivatives as antimicrobials has been virtually nonexistent. But lately, there has been growing interest in the development of newer, natural and broader spectrum of antimicrobial agents due to: the likelihood that these phytochemicals will find their way into antimicrobial drugs, the public's increasing awareness of problems associated with the abuse of traditional antibiotics leading to rapid development of resistance against chemical antibiotics by bacterial strains (Weisser et al., 1966), occurrence of undesirable side effects from some chemically synthesized drugs, scarcity and the high cost of new generation antibiotics, the growing interest by people in having more autonomy over their medicare, environmental pollution as a result of long biodegradation time of synthetic materials compared to natural substances and the rapid extinction rate of some plant species (Lewis and Elvin-Lewis, 1995) fuelling a feeling that potentially useful phytochemical structures which could be synthesized chemically are at risk of being lost irretrievably (Borris, 
1996). The first plant compound with antimicrobial activity was reported in the 1930s (Rall and Scleifer, 1991), and now a multitude of plant compounds (often of unreliable purity) are readily available over-the-counter from herbal suppliers and natural-food stores, and self-medication with these substances is common and growing in popularity (Eisenberg et al., 1993).

Microbial contamination in foods occurs during production, processing, sale and distribution (Deak and Beuchat, 1996), leading to microbial food-borne diseases (Mead et al., 1999) and food spoilage necessitating the use of antimicrobials (Sagdıc and Ozcan, 2003). Many pathogenic microorganisms, such as Escherichia coli, Staphylococcus aureus, Klebsiella pneumoniae, Listeria monocytogenes, Campylobacter jejuni, Candida spp., Zygosaccharomyces spp., Fusarium spp., Aspergillus spp., Rhizopus spp., and Penicillium spp. have been reported as the causal agents of food-borne diseases and/or food spoilage (Walker, 1988; Deak and Beuchat, 1996; Betts et al., 1999).

The antimicrobial properties of plants have been extensively investigated world wide, in Argentina, a research on 122 known plant species used for therapeutic treatments documented that compounds extracted from these plants, inhibited the growth of a wide spectra of microorganisms (Anesini and Perez, 1993; Martinez et al., 1994; Martinez et al., 1996). In Africa, traditional medicine is practiced and plants have been exploited for the treatment of many infections and diseases. In the USA, the use of natural herbal products reached $380 \%$ between 1990 and 1997 (Eisenberg et al., 1998). According to $\mathrm{WHO}$, medicinal plants would be the best source of a variety of drugs, therefore, such plants should be investigated to better understand their properties, safety and efficiency (Ellof, 1998). Plants readily synthesize substances for defense against attack by insects, herbivores and microorganisms (Majorie, 1999). Many plant extracts owe their potency to the presence of substances such as tannins, phenolics, micro elements, essential oils, peptides, unsaturated long chain aldehydes, alkaloids and so on. These substances are usually found in various parts of the plants like roots, leaves, shoots and bark (Ezeifeka et al., 2004). Many plants have therefore become sources of important drugs and the pharmaceutical industries have come to consider them as a source of bioactive agents that can be used in the preparation of synthetic medicine.

In this work, six microbial strains viz Salmonella typhi, Escherichia coli, Staphylococcus aureus, Bacillus cereus, Streptococcus thermophilus, and Lactobacillus acidophilus were investigated. The bacterium Salmonella typhi is a Gram-negative, motile, non-sporing, noncapsulated Bacillus that can be contracted through contaminated water, milk, food or fruits and vegetables or via convalescent or chronic carriers causing typhoid fever (Duguid et al., 1975). It has also been linked with zoonotic transmission via reptiles and common domestic pets (Duguid et al., 1975). Enteric fever (typhoid) is a global bacterial infection with an annual infection rate of 21.6 million and $10 \%$ fatality rate. In developing countries, typhoid is more severe due to poor hygiene, indiscriminate use of antibiotics and a rapid rise in multidrug resistance as has been reported with first line drugs chloramphenicol, ciprofloxacin and amoxycillin (Zulfigar et al., 1994). With the increase in resistance to antityphoid drugs, medicinal plants have gained popularity.

Escherichia coli are a large and diverse group of bacteria that commonly infest the lower intestine of warmblooded animals, are Gram-negative, facultative anaerobic and non-sporulating. Most strains of E. coli are harmless, but some, such as serotype 0157:H7, can cause food poisoning in humans, and are occasionally responsible for product recalls while another kind called "Shiga toxin-producing" E. coli (STEC) causes disease by making a toxin called Shiga toxin. E. coli are used as indicator organisms to test food samples for feacal contamination (Feng et al., 2002). As Gram-negative organisms, E. coli are resistant to many antibiotics that are effective against Gram-positive organisms.

Staphylococcus aureus is a facultative anaerobic, gram-positive, spherical bacterium, found in the air, dust, sewage, water, milk, food or food equipment, and on environmental surfaces, but humans or animals (skin or in the nose) are the primary reservoirs with approximately $20-30 \%$ of the general population found to be "staph carriers", (Heiyman, 2004). Each year some 500,000 patients in American hospitals contract a staphylococcal infection (McKenney et al., 1999). Depending on the strain $S$. aureus can secrete several toxins, many of which are associated with specific diseases. Staphylococcal food poisoning (staphyloenterotoxicosis/staphyloenterotoxemia) is one of the most acute conditions caused by the enterotoxins produced by $S$. aureus.

Bacillus cereus is an endemic, soil-dwelling, Grampositive, rod-shaped, facultative aerobe, sporeforming, beta hemolytic bacteria responsible for $2-5 \%$ of foodborne illnesses (Kotiranta et al., 2000) which occur due to survival of the bacterial spores when food is improperly cooked (Turnbull, 1996). This problem is compounded when food is then improperly refrigerated, allowing the spores to germinate (McKillip, 2000), grow and produce an enterotoxin, on which ingestion leads to two types of illness, diarrheal and emetic syndrome (Ehling-Schulz et al., 2004). Bacillus endospores are resistant to hostile physical and chemical conditions making them difficult to eliminate.

Lactic acid bacteria (LAB) comprise a clade of Grampositive, usually non-motile, non-spore-forming, nonrespiring rods and cocci which ferment glucose producing lactic acid as the major metabolic endproduct and are generally regarded as safe (GRAS). LAB has historically been linked with food fermentations as acidification inhibits the growth of spoilage agents. Proteinaceous bacteriocins are produced by several LAB strains and provide an additional hurdle for spoilage and pathogenic microorganisms. Streptococcus thermophilus (Streptococcus salivarius subsp. thermophilus), an LAB, found in milk and milk products, is not a probiotic (it does not survive the stomach conditions) and is generally used as a starter culture for the manufacture of fermented dairy 
products like yogurt. Lactobacillus acidophilus are rod-like, acid-loving and occur naturally in the human and animal gastrointestinal tract, mouth, and vagina where they can protect against some unhealthy organisms through production of anti-microbial substances such as acidolin, acidolphilin, lactocidin, bacteriocin, vitamin $\mathrm{K}$ and lactase (Ljungh and Wadström, 2006).

\section{MATERIALS AND METHODS}

\section{Plant materials}

Samples of sun dried mango leaves, free from insect infestation, infection or damage were obtained from Guangxi province, south of China, further dried at $50{ }^{\circ} \mathrm{C}$ overnight in an air oven, milled into fine powder by a rotary lab mill, and packed in air tight plastic pouches ready for extraction.

\section{Preparation of mango leave extracts (MLE)}

Three different extraction regimes were used in preparation of the extracts

\section{Decoction 1(De 1)}

To $30 \mathrm{~g}$ of mango leave powder in a flask, $500 \mathrm{~mL}$ of deionized water was added and heated at $50{ }^{\circ} \mathrm{C}$ under reflux for $48 \mathrm{~h}$ with constant agitation.

\section{Decoction 2 (De 2)}

To $30 \mathrm{~g}$ of mango leave powder in a flask $500 \mathrm{~mL}$ of deionized water was added and heated at boiling temperature under reflux for $3 \mathrm{~h}$.

\section{Ethanol extracts (Ee)}

To $30 \mathrm{~g}$ of mango leave powder $500 \mathrm{~mL}$ of a $50 \%$ ethanolic solution was added and heated at $60-62{ }^{\circ} \mathrm{C}$ under reflux for $1 \mathrm{~h}$ with constant stirring.

After heating, the various extracts were filtered first by a cheese cloth and finally by Whatman No. 2 filter paper (Whatman International Limited, Kent, England). The final filtrates were separately concentrated to about $10 \%$ by a vacuum rotary evaporator (Shanghai Shen Shun Biotechnology Co. Ltd) at $40{ }^{\circ} \mathrm{C}$. The concentrates were then lyophilized (F.T.S System, Stone Ridge New York). The lyophilized samples were weighed, packed in air tight plastic pouches and stored in the dark. The extraction yields were 26\%, 25\% and 24\% for De 1, De 2 and Ee respectively.

Dried lyophilized extracts were dissolved in a small amount of dimethylsulphoxide (DMSO) and topped up with distilled water to give a stock solution of $100 \mathrm{mg} / \mathrm{mL}$ which was then sterilized by micro-filtration through 0.45 $\mu \mathrm{m}$ Millipore filters and kept at $4{ }^{\circ} \mathrm{C}$ until use.

\section{Strains and media preparations}

The strains used are listed in Table 1. The bacteria were maintained and tested on Nutrient agar (NA) and broth.

Table 1: Indicator strains, sources, media and culture conditions

\begin{tabular}{|c|c|c|c|}
\hline Microorganisms & Source & Medium & $\begin{array}{l}\text { Cultivation } \\
\text { conditions }\end{array}$ \\
\hline $\begin{array}{l}\text { Escherichia coli } \\
\text { AS } 1.543\end{array}$ & MLCC & $\begin{array}{l}\text { NA, } \\
\text { EMB }\end{array}$ & $\begin{array}{l}37^{\circ} \mathrm{C}, \\
\text { aerobic }\end{array}$ \\
\hline Staphylococcus & ATCC & $\mathrm{NA}$, & $37^{\circ} \mathrm{C}$ \\
\hline aureus & 6538 & BPM & aerobic \\
\hline Bacillus cereus & $\begin{array}{l}\text { ATCC } \\
14574\end{array}$ & NA, LB & $\begin{array}{l}30{ }^{\circ} \mathrm{C}, \\
\text { aerobic }\end{array}$ \\
\hline Salmonella typhi & $\begin{array}{l}\text { CMCC } \\
50013\end{array}$ & NA, SS & $\begin{array}{l}37^{\circ} \mathrm{C}, \\
\text { aerobic }\end{array}$ \\
\hline $\begin{array}{l}\text { Streptococcus } \\
\text { thermophilus }\end{array}$ & MLCC & MRS & $\begin{array}{l}37^{\circ} \mathrm{C}, \\
\text { aerobic }\end{array}$ \\
\hline $\begin{array}{l}\text { Lactobacillus } \\
\text { acidophilus }\end{array}$ & MLCC & MRS & $\begin{array}{l}37^{\circ} \mathrm{C}, \\
\text { aerobic }\end{array}$ \\
\hline \multicolumn{4}{|c|}{$\begin{array}{l}\text { MLCC - Microbiology lab culture collectio } \\
\text { Wuxi, Jiangsu, China } \\
\text { NA - Nutrient agar } \\
\text { MRS - deMan Rogosa Sharpe } \\
\text { ATCC - American Type Culture Collection } \\
\text { SS - Salmonella Shigella Agar } \\
\text { EMB - Eosin Methylene Blue Agar } \\
\text { BPM - Baird parker Medium } \\
\text { LB - Luria Bertani broth }\end{array}$} \\
\hline
\end{tabular}

(NB) and deMan Rogosa Sharpe (MRS) for the lactic acid bacteria ( $\mathrm{LAB}$ ) all from Oxoid (Basingstoke, Hampshire, England). All other chemicals and reagents were of analytical grade obtained from Shanghai chemical reagent company (Shanghai China). For use in experiments, the organisms were sub-cultured in the respective broths at $37^{\circ} \mathrm{C}$ for $8 \mathrm{~h}$ after which they were streaked on agar media in plates and incubated at $37^{\circ} \mathrm{C}$ for $24 \mathrm{~h}$. From these plates microbial suspensions $\left(10^{6}\right)$ were made in $9 \%$ saline for use in the tests.

\section{Sensitivity test of microbial strains to MLE's}

The sensitivity test of the extracts against the selected microbial strains was determined using agar diffusion method (Russell and Furr, 1977; Irobi et al., 1996) with some slight modifications. In $90 \mathrm{~mm}$ Petri dishes the media was poured, allowed to set, inoculated with $100 \mu \mathrm{L}$ of the test organism $\left(10^{6}\right)$ spreaded evenly on the plate surface, and 3 sterile cylinders (diameter $6 \mathrm{~mm}$ ) were gently placed at equidistance from each other in a triangular form on the inoculated media. A $200 \mu \mathrm{L}$ of the filter sterilized extract solutions (stock) was then introduced into the cylinders. Normal saline was used as the negative control while Gentamycin was used as the positive control. The plates were then incubated at $37^{\circ} \mathrm{C}$ for $24 \mathrm{~h}$ after which the sensitivity of the test organisms to 
the extracts was determined by measuring the diameters of the inhibition zone surrounding the cylinders.

\section{Bacteria inhibition time course}

The MLEs were added to $100 \mathrm{~mL}$ of nutrient broth $(\mathrm{pH}$ 7.0) containing $1 \mathrm{~mL}$ of bacterial culture $\left(10^{6}\right)$, so that the final extract concentration was $10 \mathrm{mg} / \mathrm{mL}$. The nutrient broths were cultured at $37^{\circ} \mathrm{C}$ and sampled after 10,20 , $30,60,120,180$ and 360 min to determine the surviving cells by plating. The same was done for the microbial strains without the extracts (negative control) while Gentamyacin was used as the positive control. All the counts obtained, were the mean of triplicate tests.

\section{Determination of minimal inhibitory concentration (MIC)}

The MIC's of the extracts were determined using a twofold serial agar media dilutions method with slight modifications (Russell and Furr, 1977; Gulluce et al., 2003). A stock solution of the extract $(400 \mathrm{mg} / \mathrm{mL})$, was used as the highest concentration which was then diluted two-fold with distilled water and the process (dilution) was repeated down to $50 \mathrm{mg} / \mathrm{mL}$. From each of the dilutions $(400,200,100$ and $50 \mathrm{mg} / \mathrm{mL})$, an aliquot $(1 \mathrm{~mL})$ was introduced into $9 \mathrm{~mL}$ of agar media solution (lowering the actual concentrations to range from 40 to $5 \mathrm{mg} / \mathrm{mL}$ ), vortexed, introduced onto the plates, inoculated with 100 $\mu \mathrm{L}$ of the test organisms, swirled severally, left to solidify and incubated at $37^{\circ} \mathrm{C}$ for $24 \mathrm{~h}$ after which the plates were evaluated for the presence or absence of growth. Gentamycin and saline water were used as positive and negative controls respectively. MIC values were determined as the lowest concentration of the extract where absence of visible growth was recorded. The presence of one or two colonies was disregarded. All tests were carried out in triplicates.

\section{Analysis of the major phenolic compound in the mango leave extracts by reversed phase HPLC}

The lyophilized mango leave extracts for HPLC analysis were prepared according to the method of Ratraeli et al. (2002) with little modification. Approximately $1 \mathrm{~g}$ of each of the sample was partitioned twice with $160 \mathrm{~mL}$ of $n$ -
$\mathrm{BuOH} / \mathrm{H}_{2} \mathrm{O}(1: 1, \mathrm{v} / \mathrm{v})$ at room temperature. The different fractions were then concentrated using a rotary vacuum evaporator and finally dried to powder using a vacuum oven. The aqueous part, containing only free sugars and polyols, (Rastraelli et al., 2002) was out of the scope of our work. From the $\mathrm{BuOH}$ soluble portion $(28 \mathrm{mg}), 10 \mathrm{mg}$ was weighed out in a volumetric flask and topped up to the mark with methanol to give a final concentration of 1 $\mathrm{mg} / \mathrm{mL}$. A standard solution containing $1 \mathrm{mg} / \mathrm{mL}$ of mangiferin (Sigma Chemicals Co. - St. Louis, MO, USA) in methanol was also prepared. The samples/standard solutions were then micro filtered in readiness for injection.

Analysis was carried out on an Agilent 1100, equipped with an auto injector (fitted with a $100 \mu \mathrm{L}$ loop), an Agilent 1100 UV-VIS spectrophotometric detector and an Agilent Chem station data module integrator. Following are the operating conditions used. The column was a Zorbax Eclipse XDB-C 18 (250 $\quad x \quad 4.6 \quad \mathrm{~mm} \quad$ i.d $)$. Chromatographic separation was carried out using isocratic elution with two solvents [A-Acetonitrile; B- Water $12 \%$ acetic acid $(98: 2 \mathrm{v} / \mathrm{v})]$ in the ratio 15:85 (v/v). Detection wavelength was $280 \mathrm{~nm}$. Flow rate was 0.7 $\mathrm{mL} / \mathrm{min}$, and the injection volume was $10 \mu \mathrm{L}$ (Rastraelli et al., 2002).

The mango leave extracts' mangiferin was identified by chromatograms according to its retention time $\left(t_{R}\right)$ as established by the mangiferin authentic standard available. Quantization was performed by reporting the measured integration area in the calibration equation of the standard. Mangiferin was assayed as (-) epicatechin equivalent.

\section{Statistical analysis}

The test results were processed by using one-way variance analysis (ANOVA). Differences at $p<0.05$ were considered to be significant. The employed software was SAS (SAS 8.1 for windows, SAS Inc., Cary, NC, USA).

\section{RESULTS}

The yields for the various extraction modes used ranged within 24-26\% with ethanolic extract giving the lowest yield and decoction 1 the highest yield. The antimicrobial activity of the mango leave extracts against the 6 bacterial

Table 2: Microbial sensitivity to mango leaves extracts expressed as inhibition zone diameters

\begin{tabular}{|c|c|c|c|c|c|c|}
\hline \multirow[t]{2}{*}{ Samples } & \multicolumn{6}{|c|}{ Microorganisms / Inhibition zone diameter (mm) } \\
\hline & B. cereus & S. aureus & E. coli & $\begin{array}{l}\text { Salmonella } \\
\text { sp. }\end{array}$ & $\begin{array}{l}\text { S. } \\
\text { thermophilus }\end{array}$ & L. acidophilus \\
\hline De1 & $14.5 \pm 0.08 a$ & $15.5 \pm 0.08 a$ & $12.3 \pm 0.08 a$ & $15.0 \pm 0.94 a$ & $9.0 \pm 0.82 a$ & $9.0 \pm 0.82 a$ \\
\hline De 2 & $14.0 \pm 0.47 a$ & $15.3 \pm 0.08 a$ & $11.5 \pm 0.08 a$ & $13.0 \pm 0.82 a$ & $9.00 \pm 0.82 \mathrm{a}$ & $9.0 \pm 0.82 \mathrm{a}$ \\
\hline Ee & $15.0 \pm 0.82 a$ & $14.3 \pm 0.08 b$ & $11.5 \pm 0.08 a$ & $17.5 \pm 0.08 b$ & $9.00 \pm 0.82 a$ & $9.0 \pm 0.82 a$ \\
\hline $\mathrm{G}$ & 40.0 & 40.0 & 40.0 & 40.0 & 40.0 & 40.0 \\
\hline Ss & $7.0 \pm 0.5 b$ & $7.0 \pm 0.82 \mathrm{c}$ & $7.0 \pm 0.82 b$ & $7.0 \pm 0.82 c$ & $7.0 \pm 0.82 b$ & $7.0 \pm 0.82 b$ \\
\hline
\end{tabular}

Gentamyacin and saline solution were used as positive and negative controls respectively. All values are mean $(n=3)($ standard deviation). Means with the same letter are not significantly different.

De 1 - decoction 1; De 2 - decoction 2; Ee - ethanolic extract; G - Gentamyacin; Ss - Saline solution 
Table 3: MIC values of mango leave extracts against selected microorganisms

\begin{tabular}{lcccc}
\hline Samples & \multicolumn{4}{c}{ Microorganism / MIC values } \\
\cline { 2 - 5 } & B. cereus & S. aureus & E. coli & Salmonella sp. \\
\hline De 1 & $30.8 \mathrm{mg} / \mathrm{mL}$ & $18.2 \mathrm{mg} / \mathrm{mL}$ & $36.2 \mathrm{mg} / \mathrm{mL}$ & $18.2 \mathrm{mg} / \mathrm{mL}$ \\
De 2 & $18.2 \mathrm{mg} / \mathrm{mL}$ & $30.8 \mathrm{mg} / \mathrm{mL}$ & $36.2 \mathrm{mg} / \mathrm{mL}$ & $18.2 \mathrm{mg} / \mathrm{mL}$ \\
Ee & $30.8 \mathrm{mg} / \mathrm{mL}$ & $18.2 \mathrm{mg} / \mathrm{mL}$ & $36.2 \mathrm{mg} / \mathrm{mL}$ & $30.8 \mathrm{mg} / \mathrm{mL}$ \\
\hline All values are mean $(\mathrm{n}=3)($ standard deviation $)$ & & &
\end{tabular}

strains determined by the agar diffusion method are illustrated in Table 2, expressed as inhibition zone diameters while the corresponding MIC values are shown in Table 3.

The mango leave extracts showed an antimicrobial activity against both Gram-positive and Gram-negative bacteria tested at the stock concentration of $100 \mathrm{mg} / \mathrm{mL}$ and exhibited a far weaker activity against the LABs tested at the same concentration. The MIC values were only determined for the pathogenic microorganisms after having been found that the extracts had very low antimicrobial effect against the LAB.

\section{Inhibition time course of bacterial strains}

The inhibition time course of the various extracts against the four tested pathogenic strains; $E$. coli, S. typhi, $B$. cereus, and $S$. aureus that were sensitive to the MLEs are illustrated in Figures 1, 2, 3 and 4.

\section{Major polyphenol in Chinese MLE - identification and quantification using}

\section{Reversed-phase HPLC}

Various polyphenolic compounds were detected from the $n$ - $\mathrm{BuOH}$ soluble portion of the Chinese mango leave extracts as was observed from the several chromatographic peaks. But in all the extracts, one peak was abundant and most prominent in comparison with other peaks which appeared at almost insignificant levels. Identification was done by comparison of peak $t_{R}$ of the various compounds and the corresponding peak $t_{R}$ of the authentic standard. The $t_{R}$ of the most abundant compound was 9.3 min which was identified as Mangiferin based on the authentic standards $t_{R}$ (9.3 $\left.\mathrm{min}\right)$. This confirmed that mangiferin was the most abundant polyphenol in Chinese MLEs. The quantitative analysis of mangiferin was calculated from the experimental peak areas and by interpolation to the standard calibration curve and was estimated at $100 \mu \mathrm{g} / \mathrm{mL}$ in all the samples which translated to $0.01 \%$ in the crude Chinese mango leave extracts.

\section{DISCUSSION}

\section{Microbial sensitivity to mango leave extracts}

The in vitro antimicrobial potential of $M$. indica $L$. leaf extracts against the strains employed was assessed by the presence or absence of inhibition zones, zone diameters and MIC values. As can be seen in Tables 2 and 3 , the extracts from $M$. indica $L$. leaves, exhibited relatively weak antimicrobial potential against all the 6 bacterial species tested compared to the positive control (Gentamyacin). The antimicrobial activity was least against the LABs as exhibited by the small inhibition diameters of about $9.0 \mathrm{~mm}$ which is in agreement with the work of Kabuki et al. (2000). In the pathogenic category, the least activity was against $E$. coli, a Gram-negative bacterium where the inhibition zone diameters ranged between 11.5 and 12.3. This could be attributed to the cell envelope including cytoplasmic membrane and cell wall components' structural differences between Gram-positive and negative bacteria (Hugo, 1998). Because antimicrobial agents make contact with the cell envelope first, the structural difference plays a key role in the susceptibility.

For the other pathogenic organisms, the inhibition zone diameters generally ranged between 13.0 and 17.5 $\mathrm{mm}$. The positive control (Gentamyacin) exhibited far stronger antimicrobial activity with inhibition diameters $40.0 \mathrm{~mm}$ for all the test organisms. There was no significant difference $(p<0.05)$ in the activity of the various extracts suggesting that, maybe none of the extraction modes used affected the bioactive components of the mango leave extracts or that none of the extraction modes adequately extracted the bioactive components from the raw leaves.

\section{Effect of MLEs on the growth course of bacterial strains (inhibition time course)}

From Figures 1, 2, 3, and 4, the number of surviving cells decreased with the increase of incubation time. Generally compared to the positive control (Gentamyacin), the extracts exhibited weak antimicrobial activity against the tested strains but succeeded in maintaining the microbial counts below the initial count throughout the $360 \mathrm{~min}$ suggesting that the extracts probably acted as microbiostatics. E. coli, Bacillus and Salmonellas' growth courses were found to be inhibited more by ethanolic extract and least by the decoction 1 extract while $S$. aureus was the opposite, being more resistant to ethanolic extract and least to decoction 1. It was also generally found that the extracts were fast acting, with all of them registering significant initial microbial reductions within the first 20 min before maintaining an almost constant state. These data were important for developing natural preservatives in food industry. 


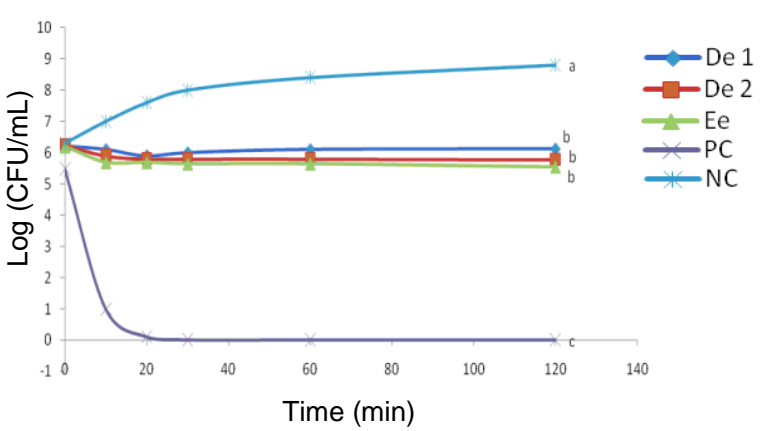

Figure 1: The antimicrobial (MLE) growth inhibition time course for E. coli AS 1.543 MLCC. Each data point represents a mean, $(n=3)$. At a chosen point marked by the same letter on different curves, there is no significant difference $(p<0.05)$. De 1 - Decoction 1, De 2 Decoction 2, Ee - Ethanolic extract, Control (P) Positive control - Gentamyacin, Control (N) - Negative c ontrol (No antimicrobial agent)

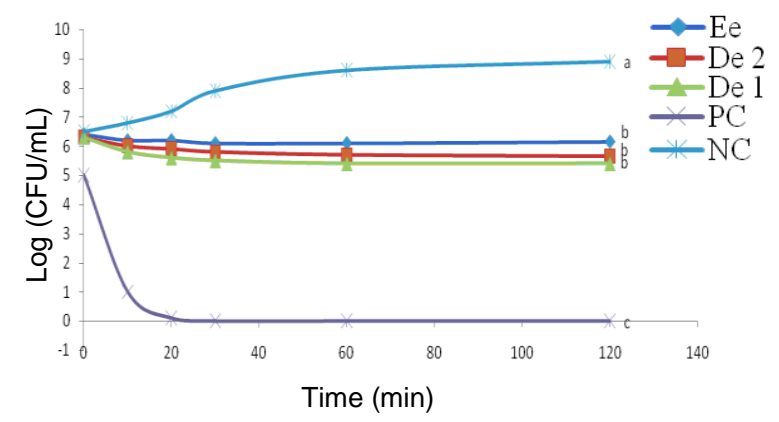

Figure 2: The antimicrobial (MLE) growth inhibition time course for $S$. aureus ATCC 6538. Each data point represents a mean, $(n=3)$. At a chosen point marked by the same letter on different curves, there is no significant difference $(p<0.05)$. De 1 - Decoction 1, De 2 Decoction 2, Ee - Ethanolic extract, Control (P) Positive control - Gentamyacin, Control (N) - Negative control (No antimicrobial agent)

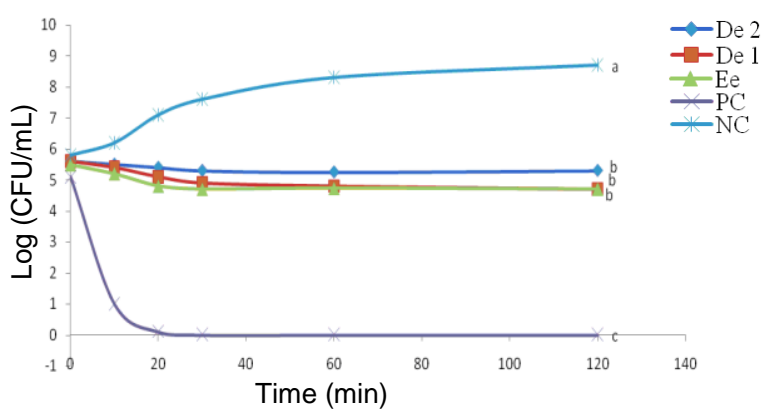

Figure 3: The antimicrobial (MLE) growth inhibition time course for $B$. cereus ATCC 14574. Each data point represents a mean, $(n=3)$. At a chosen point marked by the same letter on different curves, there is no significant difference $(\mathrm{p}<0.05)$. De 1 - Decoction 1, De 2 Decoction 2, Ee - Ethanolic extract, Control (P) Positive control - Gentamyacin, Control (N) - Negative control (No antimicrobial agent)

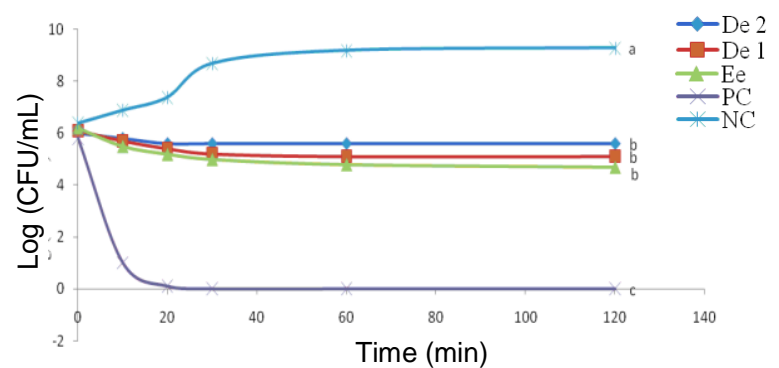

Figure 4: The antimicrobial (MLE) growth inhibition time course for S. typhi CMCC 50013. Each data point represents a mean, $(n=3)$. At a chosen point marked by the same letter on different curves, there is no significant difference $(p<0.05)$. De 1 - Decoction 1, De 2 Decoction 2, Ee - Ethanolic extract, Control (P) Positive control - Gentamyacin, Control (N) - Negative control (No antimicrobial agent)

\section{MIC values of mango leave extracts}

The MIC values were highest against $E$. coli at an average of $36.2 \mathrm{mg} / \mathrm{mL}$ while they varied from 18.2 to $30.8 \mathrm{mg} / \mathrm{mL}$ against the rest of the test organisms. The MIC values were observed to vary with the extraction mode where De 2 registered the lowest value $(18.2 \mathrm{mg} / \mathrm{mL})$ against $B$. cereus and S. typhi, De 1 being the lowest $(18.2 \mathrm{mg} / \mathrm{mL})$ against $S$. aureus and $S$. typhi while Ee was lowest (18.2 $\mathrm{mg} / \mathrm{mL}$ ) against only $S$. aureus. These results suggested that decoction is a better method of extraction, a feature that is in line with the industrial extraction of a mango stem bark extract in the manufacture of a drug called Vimang in Cuba used as a nutritional supplement (Rastraelli et al., 2002).

\section{Major polyphenol in chinese mango leave extracts}

Polyphenolic compounds have often been associated with antimicrobial and antioxidative activity (Kabuki et al., 2000). From the various research work done and published articles on the mango leaves, bark, pulp, peel and seed, the various mango parts have been found to contain various polyphenolic compounds like catechins, quercetin, gallic acid, ellagic acid, tannins and more abundantly mangiferin amongst others (Saleh and ElAnsari, 1975). In this work, it was assumed that the polyphenols present in the mango leaves were responsible for the antimicrobial activity registered but the low activity registered in our work relative to published work could be attributed to the effect of variety, geographic location and stage of maturity of the mango trees.

Lyophilized mango ( $M$. indica. L) leave extracts sourced from Guangxi province in south China were analyzed by reversed-phase HPLC with the primary intention of identification and quantification of mangiferin, the potent polyphenol in the mango (Nunez-Selles, 2005; Masibo and $\mathrm{He}, 2008)$. The extracts were partitioned twice using $n-\mathrm{BuOH} / \mathrm{H} 2 \mathrm{O}$ and the $\mathrm{BuOH}$ soluble portion submitted to reversed phase HPLC where various 
compounds were detected. In all the samples analyzed, one peak was very prominent compared to others that appeared at very low levels denoting their small quantities in the Chinese MLE's. By chromatographic comparison of $t_{R}$ with an authentic standard of mangiferin available, the prominent peak was identified as mangiferin ( $\left.t_{R} 9.3 \mathrm{~min}\right)$. This was also corroborated by comparison with published data (Rastraelli et al., 2002). The equivalence of the amounts of mangiferin $(100 \mu \mathrm{g} / \mathrm{mL})$ in all the three samples extracted under different conditions of temperature, time and extraction solvents, points out that the extraction regime had no effect on the concentration of mangiferin but on the possible number of compounds in an extract as was seen from the number of peaks detected, where De 2 had the highest number of peaks while De 1, the least. This suggested that extraction time probably the total number of compounds (peaks) directly in the extract because De 1 was extracted for $48 \mathrm{~h}$ as compared to De 2 which was extracted for $3 \mathrm{~h}$.

\section{CONCLUSIONS}

Mango is a very popular, evergreen leafy tropical tree whereby the juicy fruits are enjoyed by many people but its leaves left to waste leaving room for their industrial utilization to enjoy a cheap supply of this raw material. Several articles have been published about bioactivity of extracts from the various mango parts in Brazil, Cuba and India but little is documented about mango leave extracts from other regions. From this work, we established that leaf extracts of $M$. indica. $L$ posseses mild antimicrobial activity against $S$. typhi, E. coli, $S$. aureus, and B. cereus but surprisingly managed to hold the bacterial growth below the initial number for the 360 min test time as compared to the negative controls thus exhibiting that the extracts act as bacteriostatic agents. The antimicrobial activity of the extracts was milder against LAB's. Mangiferin was the abundant polyphenol in the Chinese mango leaf extracts and its quantity was not affected by the mode of extraction. Similarly there was no significant difference in the antimicrobial activity of the extracts suggesting that the extraction modes did not affect their bioactivity. The relatively weak antimicrobial activity of the Chinese mango leaf extracts compared to published work suggested that Geographic location affects the activity and quantity of mangiferin. The leaf extracts of Chinese mango can thus be proposed for use as mild antimicrobials in food.

\section{REFERENCES}

Anesini, E. and Perez, C. (1993). Screening of plants used in Argentine folk medicine for antimicrobial activity. Journal of Ethnopharmacology 39, 119-128.

Betts, G.D., Linton, P. and Betteridge, R. J. (1999). Food spoilage yeasts: effects of $\mathrm{pH}, \mathrm{NaCl}$ and temperature on growth. Food Control 10, 27-33.

Borris, R. P. (1996). Natural products research: perspectives from a major pharmaceutical company. Journal of Ethnopharmacology 51, 29-38.
Deak, T. and Beuchat, L. R. (1996). Handbook of food spoilage. CRC Press. New York, USA. pp. 199.

Duguid, J. P., Anderson, E. S., Alfredsson, G. A., Barker, R. and Old, D. C. (1975). A new biotyping scheme for Salmonella typhimurium and its phylogenetic significance. Journal of Medical Microbiology 8, 149-166.

Ehling-Schulz, M., Fricker, M. and Scherer, S. (2004). Bacillus cereus, the causative agent of an emetic type of food-borne illness. Molecular Nutrition and Food Research 48, 479-487.

Eisenberg, D. M., Davis, R. B. and Ettner, S. L. (1998). Trends in alternative medicine use in the US, 19901997. Journal of American Medical Association 80, 1569-1575.

Eisenberg, D. M., Kessler, R. C., Foster, C., Norlock, F. E., Calkins, D. R. and Delbanco, T. L. (1993). Unconventional medicine in the United States: Prevalence, costs and patterns of use. The New England Journal of Medicine (NEJM) 328, 246-252.

Ellof, J. N. (1998). Which extractant should be used for the screening and isolation of antimicrobial components from plants? Journal of Ethnopharmacology 60, 1-6.

Ezeifeka, G., Orji, M., Mbata, T. and Patrick, A. (2004). Antimicrobial activity of Cajanus cajan, Garcinia kola and Xylopia aethiopica on pathogenic microorganisms. Biotechnology 3, 41-43.

Feng, P., Weagant, S. and Grant, M. (2002). Enumeration of Escherichia coli and the Coliform bacteria. In: Bacteriological Analytical Manual FDA/Center for Food Safety \& Applied Nutrition.

Gulluce, M., Sokmen, M., Daferera, D., Ag ar, G., Ozkan, H., Kartal, N., Polissiou, M., Sokmen, A. and Sahin, F. (2003). In vitro antibacterial, antifungal and antioxidant activities of the essential oil and methanol extracts of herbal parts and callus cultures of Satureja hortensis L. Journal of Agricultural and Food Chemistry 51, 3958-3965.

Heiyman, D. (2004). Control of Communicable Diseases Manual. $18^{\text {th }}$ ed. American Public Health Association, Washington DC.

Hugo, W. B. (1998). Bacteria. In: Pharmaceutical microbiology. Hugo, W. B. and Russell, A. D. (eds.). Oxford, Blackwell Scientifc Publications.

Irobi, O. N., Moo-Young, M. and Anderson, W. A. (1996). Antimicrobial activity of Annatto (Bixa orellana) extract. International Journal of Pharmacognosy 34, 87-90.

Kabuki, T., Nakajima, H., Arai, M., Ueda, S., Kuwabara, Y. and Dosako, S. I. (2000). Characterization of novel antimicrobial compounds from mango (Mangifera indica L.) kernel seeds. Food Chemistry 71, 61-66.

Kotiranta, A., Lounatmaa, K. and Haapasalo, M. (2000). Epidemiology and pathogenesis of Bacillus cereus infections. Microbes and Infection 2, 189-198.

Lewis, W. H. and Elvin-Lewis, M. P. (1995). Medicinal plants as sources of new therapeutics. Annals of the Missouri Botanical Garden 82, 16-24. 
Ljungh, A. and Wadström, T. (2006). Lactic acid bacteria as probiotics. Current Issues in Intestinal Microbiology 7, 73-89.

Majorie, M. C. (1999). Plant products as antimicrobial agents. Clinical Microbiol. Revision 12, 564-582.

Martinez, M. J., Betancourt, J., Alonso-Gonzalez, N. and Jauregui (1996). A. Screening of some Cuban medicinal plants for antimicrobial activity. Journal of Ethnopharmacology 52, 171-174.

Martinez, M. J., Vasquez, S. M., Espinosa-Perez, C., Dias, M. and Herrera-Sanchez, M. (1994). Antimicrobial properties of argentatine $A$ isolated from Parthenium argentatum. Fitoterapia 65, 371-372.

Masibo, M. and He, Q. (2008). Major mango polyphenols and their potential significance to human health. Comprehensive Reviews in Food Science and Food Safety 7, 309-319.

McKenney, D., Pouliot, K. L., Wang, Y., Murthy, V., Ulrich, M., Döring, G., Lee, J.C., Goldmann, D. A. and B, P. G. (1999). Broadly protective vaccine for Staphylococcus aureus based on an in vivoexpressed antigen. Science 284, 1523-1527.

McKillip, J. L. (2000). Prevalence and expression of enterotoxins in Bacillus cereus and other Bacillus spp., a literature review. Antonie Van Leeuwenhoek 77, 393-399.

Mead, P. S., Slutsker, L., Dietz, V., McCaig, L. F., Breese, J. S., Shapiro, C., Griffin, P. M. and Tauxe, R. V. (1999). Food related illness and death in the United States. Emerging Infectious Diseases 5, 607625.

Nunez-Selles, A. J. (2005). Antioxidant Therapy: Myth or reality? Journal of Brazilian Chemical Society 16, 699-710.

Puravankara, D., Bohgra, V. and Sharma, R.S. (2000). Effect of antioxidant principles isolated from mango (Mangifera indica L.) seed kernels on oxidative stability of buffalo ghee (Butter-Fat). Journal of Science of Food and Agriculture 80, 522-526.

Rall, T.W. and Scleifer, L.S. (1991). Fármacos efectivos en el tratamiento de la epilepsia. In: Las bases farmacológicas de la terapéutica. Goodman, G. A., Rall, I. W., Nies, A. S. and Taylor (eds.). Goodman y Gilman, P. México. pp. 444.

Rastraelli, L., Selles, A. J. N., Castro, H. T. V., AgueroAguero, J., Gonzalez-Gonzalez, J., Naddeo, F. and Simone, F. D. (2002). Isolation and quantitative analysis of phenolic antioxidants, free sugars, and polyols from mango (Mangifera indica L.) stem bark aqueous decoction used in Cuba as a nutritional supplement. Journal of Agriculture and Food Chemistry 50, 762-766.

Russell, A. D. and Furr, J. R. (1977). Antibacterial activity of a new chloroxylenol preparation containing ethylenediamine tetraacetic acid. Journal of Applied Bacteriology 43, 253-260.

Sagdıc, O. and Ozcan, M. (2003). Antibacterial activity of Turkish spice hydrosols. Food Control 14, 141-143.
Saleh, N. A. M. and El-Ansari, M. A. I. (1975). Polyphenolics of twenty local verities of Mangifera indica. Planta Medica 28, 124-130.

Turnbull, P. C. B. (1996). Bacillus. In: Baron's Medical Microbiology. Barron, S. (ed.). Univ of Texas Medical Branch, Texas.

Walker, S. J. (1988). Major spoilage micro-organisms in milk and dairy products. Journal of the Society of Dairy Technology 41, 91-92.

Weisser, R., Asscher, A. and Winpenny, J. (1966). In vitro reversal of antibiotic resistance by DTA. Nature 219, 1365-1366.

Zulfigar, A., Tikki, P., Bhutta, B., Finly, B. and Altwegg, M. (1994). Typhoid fever and other salmonellosis, a continuing challenge. Trends Microbiology 3, 253256. 